03

\title{
Анализ жидко-кластерного состояния расплавов вблизи температуры плавления
}

\author{
() В.Д. Александров, А.П. Зозуля, Е.А. Покинтелица, Н.В. Щебетовская
}

Донбасская национальная академия строительства и архитектуры,

286123 Макеевка, Украина

e-mail: Ink0013@gmail.com

Поступило в Редакцию 30 сентября 2019 г.

В окончательной редакции 11 декабря 2019 г.

Принята к публикации 5 июля 2020 г.

Проанализированы известные данные о переходе от равновесной кристаллизации расплавов различных веществ к неравновесно-взрывной в зависимости от предварительных прогревов жидкой фазы до температуры $T_{C}^{+}$. Интервал перегревов $\Delta T_{L}^{+}=T_{C}^{+}-T_{L}$ относительно температуры плавления $T_{L}$ по аналогии с жидкокристаллическим состоянием отнесен к области существования мезофазы, описываемой параметром порядка $Q$. Дан сравнительный анализ зависимости изменения свободной энергии от параметра порядка для кластеров в мезофазе и от размеров кристаллических зародышей в метастабильной области ниже температуры плавления.

Ключевые слова: жидкая фаза, мезофаза, твердая фаза, перегрев, переохлаждение, кристаллизация, свободная энергия, параметр порядка, кластеры, зародыши.

DOI: 10.21883/JTF.2020.12.50117.321-19

\section{Введение}

В литературе большое внимание уделяется кластерному строению расплавов вблизи температуры плавления, так как от его состояния зависят структура и свойства твердой фазы [1-7]. Вместе с тем практически отсутствуют исследования границ существования кристаллоподобных кластеров и процессов их образования из жидкой фазы. Такими границами могут служить перегревы расплавов. Перегрев расплава относительно температуры плавления является важнейшей характеристикой процесса кристаллизации [1-3]. От величины перегрева зависит предкристаллизационное переохлаждение , вследствие чего меняется характер кристаллизации. Такая зависимость есть прямое доказательство взаимосвязи между строением жидкости и структурой кристаллов, образующихся из нее.

Объектами внимания в настоящей работе являются относительно небольшие макроскопические вещества объемами $0.1-0.5 \mathrm{~cm}^{3}$, кристаллизующиеся в нормальных условиях.

В литературе имеется большое число работ, посвященных влиянию термической предыстории расплавов подобных объектов на переохлаждение и кинетику кристаллизации $[4,7-6]$.

В то же время из-за применения различных методик и отсутствия систематических исследований методами термического анализа на графиках зависимости $\Delta T^{-}$от $\Delta T^{+}$, как правило, дается большой разброс точек, по которым трудно судить о четкой зависимости переохлаждения от перегрева.

\section{1. Экспериментальные результаты}

Для исследований влияния перегрева $\Delta T^{+}$на переохлаждение $\Delta T^{-}$нами была разработана методика циклического термического анализа (ЦТА), суть которой заключается в непрерывном термоциклировании объектов в заданном температурном интервале с сохранением нижней границы циклов и последовательном изменении верхней границы цикла выше (либо ниже) предыдущего [17,18]. Пользуясь этой методикой, мы проводили многочисленные эксперименты по влиянию прогрева жидкой фазы на степень переохлаждения на разнообразных веществах - металлах и сплавах, химических соединениях, кристаллогидратах, низкомолекулярных органических веществах [3].

В результате подобных исследований были выявлены следующие закономерности:

- обнаружен быстрый переход от квазиравновесной кристаллизации (ЕС) с практически отсутствием переохлаждения к неравновесно-взрывной (NEC) со средним переохлаждением $\left\langle\Delta T_{s t}^{-}\right\rangle$;

- установлено, что этот эффект связан с определенным критическим прогревом жидкой фазы до температуры $T_{C}^{+}$, недогретый до $T_{C}^{+}$расплав кристаллизуется при охлаждении по типу ЕС, а прогретый выше $T_{C}^{+}-$по типу NEC;

- средние переохлаждения $\left\langle\Delta T_{s t}^{-}\right\rangle$не зависят от дальнейшего увеличения прогрева расплава выше температуры $T_{C}^{+}$;

- область температур в интервале от $T_{L}$ до $T_{C}^{+}$отнесена к мезофазе.

Данный эффект трактуется с точки зрения кластернокоагуляционной модели кристаллизации [3], согласно 
Таблица 1. Температуры плавления, перегревы и переохлаждения некоторых химических элементов и соединений

\begin{tabular}{|c|c|c|c|c|}
\hline Вещество & $T_{L}, \mathrm{~K}$ & $T_{C}^{+}, \mathrm{K}$ & $\Delta T_{L}^{+}, \mathrm{K}$ & $\Delta T_{s t}^{-}, \mathrm{K}$ \\
\hline $\mathrm{Ga}$ & 302.9 & $312.9-317.9$ & $10-15$ & $\sim 35$ \\
\hline Sn & 505.1 & $509.1-510.5$ & $4-5$ & $7-10$ \\
\hline $\mathrm{Bi}$ & 544.6 & $549.6-554.6$ & $5-10$ & до 30 \\
\hline $\mathrm{Sb}$ & 903.9 & $913.9-915.9$ & $10-12$ & $55-65$ \\
\hline $\mathrm{S}$ & 392.0 & $400.0-402.0$ & $8-10$ & $20-60$ \\
\hline $\mathrm{Se}$ & 490.0 & $497.0-500.0$ & $7-10$ & $\sim 30-60$ \\
\hline $\mathrm{Te}$ & 723.0 & $733.0-735.0$ & $10-12$ & $90-120$ \\
\hline InBi & 383.0 & $387.0-378.0$ & $4-5$ & $16 \pm 2$ \\
\hline $\mathrm{InSb}$ & 525.0 & $\sim 555.0$ & $\sim 30$ & $40-42$ \\
\hline $\mathrm{PbCl}_{2}$ & 438.0 & $\sim 443.0$ & $\sim 5$ & $\sim 24$ \\
\hline $\mathrm{Ag}_{3} \mathrm{AsS}_{3}$ & $498 \pm 3$ & $\sim 512 \pm 3$ & $\sim 14$ & $\sim 80$ \\
\hline $\mathrm{H}_{2} \mathrm{O}$ & 273.0 & $\sim 277.0$ & $\sim 4$ & $7-10$ \\
\hline $\mathrm{Na}_{2} \mathrm{~S}_{2} \mathrm{O}_{3} \cdot 5 \mathrm{H}_{2} \mathrm{O}$ & 321.0 & 339.0 & $\sim 18$ & до 45 \\
\hline $\mathrm{Na}_{2} \mathrm{SO}_{3} \cdot 7 \mathrm{H}_{2} \mathrm{O}$ & 306.5 & $\sim 324.5$ & $\sim 18$ & $25-27$ \\
\hline $\mathrm{Na}_{2} \mathrm{SO}_{4} \cdot 10 \mathrm{H}_{2} \mathrm{O}$ & 305.4 & $\sim 320.4$ & $\sim 15$ & $14-18$ \\
\hline $\mathrm{Na}_{2} \mathrm{CO}_{3} \cdot 10 \mathrm{H}_{2} \mathrm{O}$ & 305.0 & $\sim 314.0$ & $\sim 9$ & $\sim 13$ \\
\hline $\mathrm{NaCH}_{3} \mathrm{COO} \cdot 3 \mathrm{H}_{2} \mathrm{O}$ & 331.0 & $338.0-340.0$ & $7-9$ & $72-82$ \\
\hline бензол & 378.6 & $\sim 382.6$ & $\sim 4$ & $6-10$ \\
\hline фенол & 313.5 & $316.5-317.5$ & $3-4$ & $10-23$ \\
\hline нафталин & 353.5 & $356.5-358.5$ & $3-5$ & $\sim 10$ \\
\hline дифенил & 343.5 & $\sim 348.5$ & $\sim 5$ & $\sim 10$ \\
\hline дибензил & 325.5 & $327.5-328.5$ & $2-3$ & $20-24$ \\
\hline о-терфенил & 329.3 & $332.3-334.3$ & $3-5$ & $30-34$ \\
\hline m-терфенил & 360.5 & $\sim 362.5$ & $\sim 2$ & $\sim 37$ \\
\hline пирокатехин & 378.0 & $380.0-381.0$ & $2-3$ & $20-40$ \\
\hline резорцин & 383.8 & $387.8-389.8$ & $4-6$ & $55-65$ \\
\hline $\begin{array}{l}\text { 3-метил-4-нитро- } \\
\text { пиридин-1-оксид }\end{array}$ & 408 & $416-417$ & $8-9$ & $9-10$ \\
\hline
\end{tabular}

которой в слабо прогретом расплаве вблизи температуры плавления (т. е. в области мезофазы) сохраняются кристаллоподобные кластеры. При охлаждении такой жидкости кристаллизация носит квазиравновесный характер практически с отсутствием переохлаждения. При большем прогреве (выше $T_{C}^{+}$) эти кластеры окончательно разрушаются. В процессе охлаждения от изотропной жидкости идет обратный процесс налаживания утраченных связей за определенный инкубационный период. Достигнув некоторой предельной концентрации кластеров, последние коагулируют, вызывая стартовую быструю кристаллизацию из переохлажденного состояния.

В табл. 1 для ряда веществ сведены следующие данные: справочные энтальпии $\Delta H$ и температуры $T_{L}$ плавления [3,19], а также температуры прогрева жидкой фазы $T_{C}^{+}$, критические перегревы $\Delta T_{L}^{+}$и разброс переохлаждений $\Delta T_{s t}^{-}$, полученные практически в одних и тех же условиях эксперимента [3].

В качестве примеров, характеризующих быстрый переход от ЕС к NEC или наоборот, на рис. 1 приведены фрагменты термограмм теллура $(a)$, висмута $(b)$, воды $(c)$ и „жидкого кристалла“ 3-метил-4-нитропиридин- 1-оксида $(d)$, отражающие скачкообразный переход от взрывной кристаллизации к равновесной.

На термограммах показаны предельные температуры $T_{C}^{+}$нагрева расплава, являющиеся как бы водоразделом для последующих видов кристаллизации. Кроме того, видно, что при дальнейшем повышении температуры расплава $\left(T>T_{C}^{+}\right)$и охлаждении от этой температуры, кристаллизация остается неравновесной с прежним переохлаждением.

На основании многочисленных термоциклов нагревания и охлаждения как на одном образце, так и на нескольких образцах одинаковой массы строились графики зависимости $\Delta T^{-}$от $\Delta T^{+}$, характеризующие быстрый переход от ЕС к NEC.

Математическую зависимость средних значений $\left\langle\Delta T^{-}\right\rangle$от $\left\langle\Delta T^{+}\right\rangle$в этих примерах можно представить в виде

$$
\left\langle\Delta T^{-}\right\rangle=\left\langle\Delta T_{s t}^{-}\right\rangle \Theta\left(\Delta T^{+}-\Delta T_{C}^{+}\right),
$$

где $\Theta-$ ступенчатая функция Хевисайда:

$$
\Theta= \begin{cases}0, & \Delta T^{+}<\Delta T_{C}^{+}, \\ 1, & \Delta T^{+} \geq \Delta T_{C}^{+} .\end{cases}
$$

Обобщая данные по эффекту перехода от одного типа кристаллизации (EC) к другому (NEC) в зависимости от предварительного прогрева жидкой фазы, нарисуем ряд схематических последовательных термоциклов нагревания и охлаждения (рис. 2). Условно покажем на нем области жидкой фазы $(L)$, мезофазы $(M)$, метастабильного $(N)$ и твердого $(S)$ состояний, разделенных друг от друга пунктирными горизонтальными линиями. Первая термограмма относится к процессу плавления без перегрева, вторая и третья - к случаям небольших прогревов $\left(T_{L}<T<T_{C}^{+}\right)$жидкой фазы. В примерах I-III кристаллизация при охлаждении носит равновесный характер без переохлаждения. Термограмма IV отражает некий „критический“ перегрев $\Delta T_{C}^{+}$расплава, после которого при охлаждении резко меняется тип кристаллизации от ЕC к NEC из переохлажденного состояния. Достигнув за период времени $\tau_{1}$ предельного переохлаждения $\Delta T_{s t}^{-}$, температура за время $\tau_{2}$ быстро поднимается до температуры плавления $T_{L}$ (от точки $e$ до точки $d$ ) на величину $\Delta T^{-}$. На заключительной стадии за время $\tau_{3}$ наблюдается горизонтальное плато $\left(d d^{\prime}\right)$ кристаллизации с последующим охлаждением твердой фазы по линии $(d / f)$.

\section{2. Анализ и обсуждение результатов}

Область сосуществования жидкости с кристаллоподобными кластерами напоминает жидко-кристаллическое состояние (мезофазу $M$ ), характерное для классических жидких кристаллов [20], которые имеют две температуры плавления. В нашем случае также имеются как бы две температуры плавления - основная $T_{L}$ и 

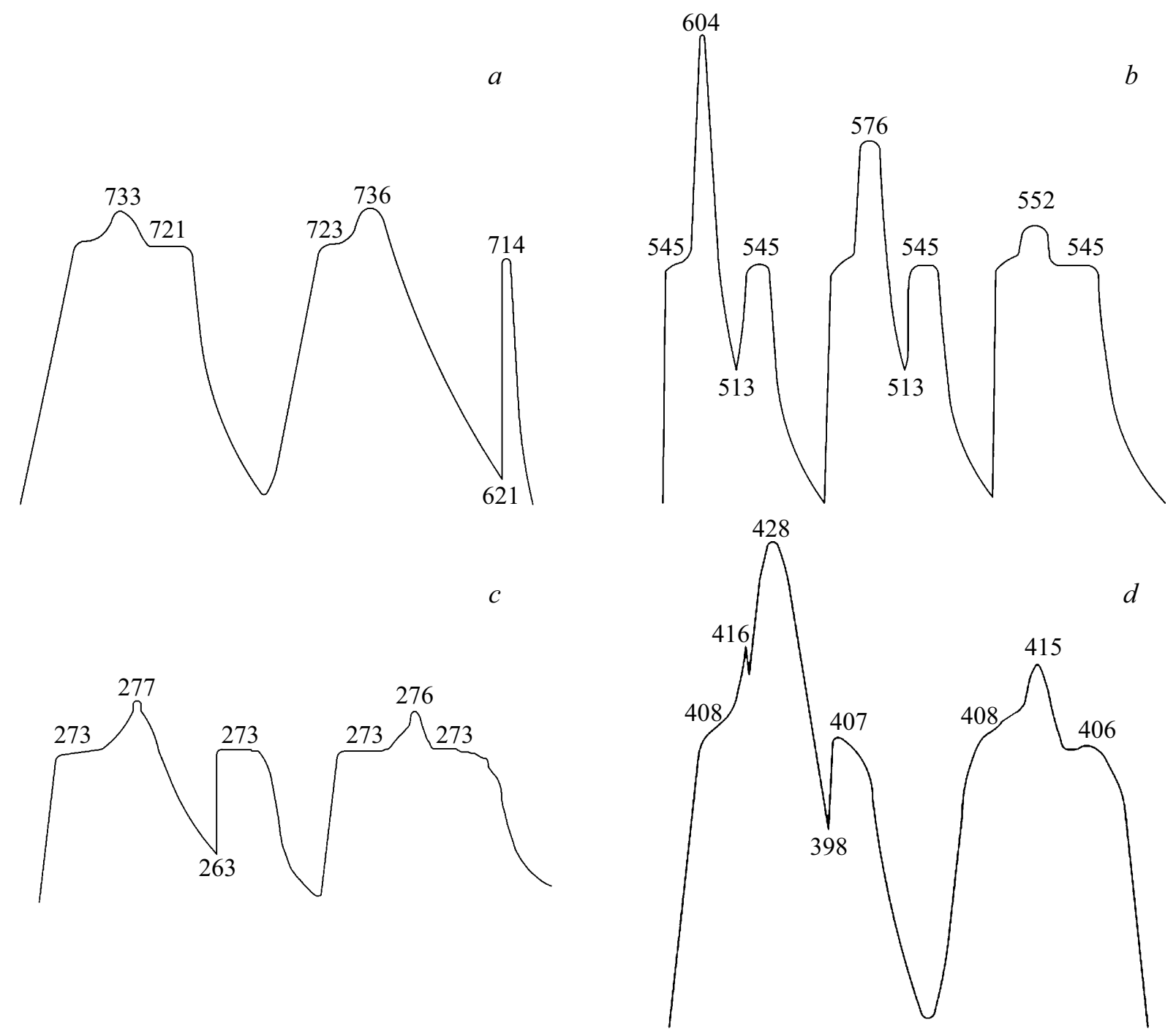

Рис. 1. Термоциклы нагревания и охлаждения теллура $(a)$, висмута $(b)$, воды $(c)$ и 3-метил-4-нитропиридин-1-оксида $(d)$. На термограммах приведены температуры в градусах Кельвина.

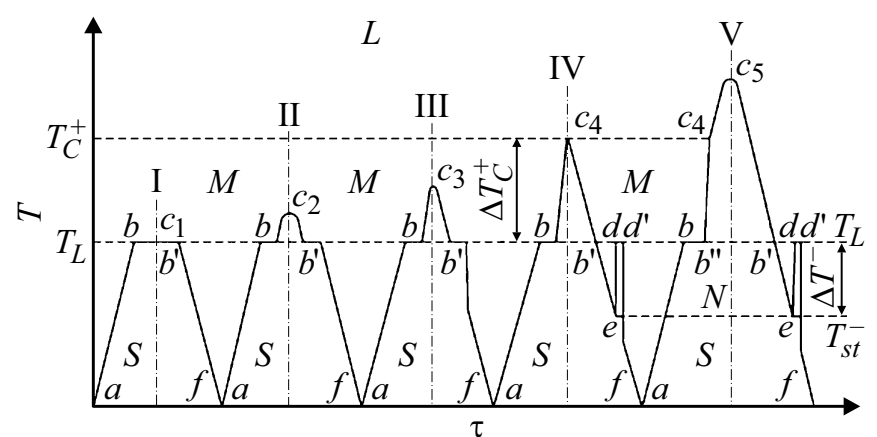

Рис. 2. Схематические термоциклы, характеризующие переход от ЕC (I-III) к NEC (IV-V). Обозначения $L-$ liquid, $S-$ solid, $M-$ mezophase, $N-$ nucleus.

окончательная $T_{C}^{+}$, при которой мезофаза переходит в „идеальное“ изотропное состояние $L$.
Специально для настоящей работы нами были проведены исследования по влиянию перегрева на переохлаждение на одном из представителей жидких кристаллов - 3-метил-4-нитропиридин-1-оксиде (рис. $1, d$ ) массой $0.5 \mathrm{~g}$ по стандартной методике [3]. Видно, что при нагревании фиксируется два тепловых эффекта: один при $T_{L} \approx 408 \mathrm{~K}$, а второй - при $T_{C}^{+} \approx 416 \mathrm{~K}$. При охлаждении от температуры $428 \mathrm{~K}$ наблюдается кристаллизация типа NEC с переохлаждением $\sim 9-10 \mathrm{~K}$, а при охлаждении от температуры $415 \mathrm{~K}$ - кристаллизация типа ЕС с незначительным переохлаждением $\sim 0.2 \mathrm{~K}$.

Таким образом, критические температуры $T_{C}^{+}$характеризуют верхнюю границу, а температуры плавления $T_{L}$ - нижнюю границу жидко-кластерного состояния.

Термодинамическое условие устойчивости той или иной фазы представляют на основании температурных зависимостей свободных энергий [21]: 


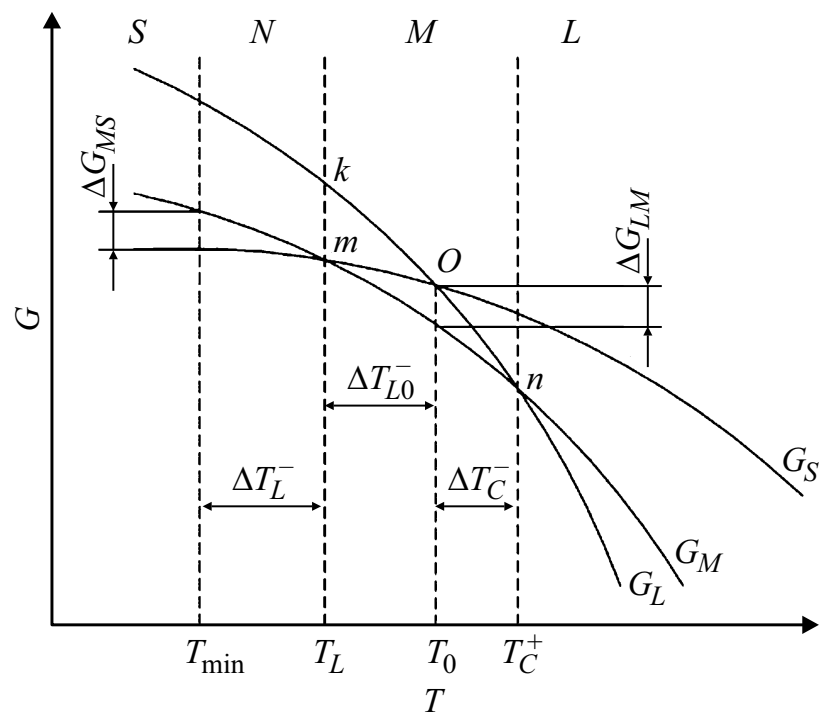

Pис. 3. Зависимости энергий Гиббса для жидкой $\left(G_{L}\right)$, твердой $\left(G_{S}\right)$ и жидко-твердой $\left(G_{M}\right)$ фаз от температуры.

- для жидкой $(L)$ фазы

$$
G_{L}=H_{L}-T S_{L}=H_{L}-T \int\left(c_{p}^{L} / T\right) d T,
$$

где $c_{p}^{L}=a^{\prime}+b^{\prime} T+c^{\prime} T^{2}$

- для твердой $(S)$ фазы

$$
G_{S}=H_{S}-T S_{S}=H_{S}-T \int\left(c_{p}^{S} / T\right) d T,
$$

где $c_{p}^{S}=a^{\prime \prime}+b^{\prime \prime} T+c^{\prime \prime} T^{2} ; H_{L}, H_{S}$ - энтальпии и $c_{p}^{L}$, $c_{p}^{S}$ - удельные теплоемкости жидкой и твердой фаз; $a, b, c$ со штрихами - постоянные коэффициенты.

В отсутствие мезофазы эти кривые пересекаются в точке $O$, относящейся к одной температуре плавления $T_{o}$ (рис. 3). Введем еще одну характеристику, а именно энергию Гиббса для жидко-кластерного состояния $G_{M}(T)$ :

$$
G_{M}=H_{M}-T S_{M}=H_{M}-T \int\left(c_{p}^{M} / T\right) d T,
$$

где $c_{p}^{M}=a^{\prime \prime}+b^{\prime \prime} T+c^{\prime \prime} T^{2}, H_{M}, c_{p}^{M}-$ энтальпия и удельная теплоемкость мезофазы.

Эта кривая должна удовлетворять основным требованиям термодинамического равновесия и поэтому пересекает кривые $G_{L}$ и $G_{S}$ в точках $m$ и $n$ (рис. 3 ), соответствующих температурам $T_{L}$ и $T_{C}^{+}$. Ниже температуры плавления устойчива твердая фаза, так как $G_{S}<G_{M}<G_{L}$, а выше температуры $T_{C}^{+}$- жидкая фаза, так как $G_{S}>G_{M}>G_{L}$. На участке $m n$ между температурами $T_{L}$ и $T_{C}$ термодинамически устойчива мезофаза. Видно, что в этой области $G_{M}<G_{S}$ и $G_{M}<G_{L}$. В то же время основная температура плавления сдвигается из точки $O$ в точку $m$.
Кроме того, вблизи температуры $T_{L}$ могут происходить фазовые переходы $S \leftrightarrow M$, а вблизи температуры $T_{C}^{+}$- переходы $L \leftrightarrow M$ с соответствующими „движущими силами“ $\Delta G_{L M}$ и $\Delta G_{M S}$ (рис. 3 ), что свидетельствует о возможности существования термических гистерезисных явлений при нагревании и охлаждении [22].

Значения свободных энергий $\Delta G$ используют, в частности, для вычисления размеров зародышей кристаллов и работы их образования в метастабильной области ниже температуры плавления [1,2]. Однако в случае с кластерами, состоящими из нескольких атомов или молекул, выражение зависимости $\Delta G$ от $l$ [1] вряд ли уместны, так как при этом должны использоваться такие макроскопические характеристики, как энтальпия плавления и межфазная поверхностная энергия, которые нельзя определить для агрегатов малых размеров.

Для анализа свободной энергии для случая образования кластеров в мезофазе можно воспользоваться представлениями о так называемом параметре порядка, используемого в феноменологической теории жидких кристаллов. [20,23]. Параметр порядка имеет вид

$$
Q_{i j}=Q\left(n_{i} n_{j}-(1 / 3) \delta_{i j}\right),
$$

где $\mathbf{n}$ - директор, характеризующий упорядочение молекул в макроскопическом объеме жидких кристаллов; $Q$ - скалярная величина, дающая долю молекул, направленных вдоль определенного направления; $n_{i} n_{j}-$ компоненты директора; $\delta_{i j}-$ символ Кронекера: $\delta=1$ при $i=j$ и $\delta_{i j}=0$ при $i \neq j$.

Подобный подход к состоянию жидкость-кристаллоподобные кластеры (область $M$ на рис. 3) также обоснован, так как в результате плавления анизотропного кристалла вначале разрушаются наименее прочные, а затем более прочные связи между молекулами. Это приводит к тому, что вблизи температуры плавления сохраняется определенный порядок в расположении молекул с незначительным изменением координационных чисел $[4,24,25]$.

Как известно, для вычисления параметра порядка $Q$ можно использовать анизотропию различных физических свойств кристаллов [20]. В нашем случае воспользуемся энергиями связей $U_{a}, U_{b}, U_{c}$ между молекулами вдоль различных кристаллографических направлений. Например, при $U_{b}>U_{a}=U_{c}$

$$
Q=\left(U_{B}-U_{a}\right) / \Delta U_{b},
$$

где $a, b, c$ - параметры решетки кристалла, $\Delta U_{b}-$ максимальная величина изменения энергии по направлению наиболее сильной связи.

Разложение свободной энергии по степеням параметpa $Q$ [23] дает уравнение для области мезофазы:

$$
G_{M}=G_{L}+U_{a} Q^{2}-U_{b} Q^{3}+U_{c} Q^{4},
$$

откуда движущая сила фазового превращения от изотропной жидкости $L \kappa$ мезофазе $M$ будет равна

$$
\Delta G_{L M}=U_{a} Q^{2}-U_{b} Q^{3}+U_{c} Q^{4}
$$


Таблица 2. Справочные физические характеристики и расчетные значения $A_{N}$ для $\mathrm{Sn}, \mathrm{Bi}, \mathrm{H}_{2} \mathrm{O}$ и $\mathrm{C}_{10} \mathrm{H}_{8}$

\begin{tabular}{c|c|c|c|c|c|c|c|c}
\hline Вещество & $T_{L}, \mathrm{~K}$ & $\Delta H, \mathrm{~kJ} / \mathrm{kg}$ & $\sigma, \mathrm{mJ} / \mathrm{m}^{2}$ & $c_{p}, \mathrm{~J} / \mathrm{kg} \cdot \mathrm{K}$ & $\begin{array}{c}\rho_{S}, 10^{3} \\
\mathrm{~kg} / \mathrm{m}^{3}\end{array}$ & $\begin{array}{c}\rho_{L}, 10^{3} \\
\mathrm{~kg} / \mathrm{m}^{3}\end{array}$ & $\begin{array}{c}\Delta \rho, 10^{3} \\
\mathrm{~kg} / \mathrm{m}^{3}\end{array}$ & $\begin{array}{c}A_{N}, \mathrm{eV} \\
\mathrm{Sn}\end{array}$ \\
$\mathrm{Bi}$ & 505.1 & 59.6 & 59.0 & 247.8 & 7.80 & 7.0 & 0.80 & 0.444 \\
$\mathrm{H}_{2} \mathrm{O}$ & 273.0 & 335.0 & 34.4 & 146.2 & 10.70 & 9.8 & 0.92 & 0.195 \\
$\mathrm{C}_{10} \mathrm{H}_{8}$ & 353.5 & 146.9 & 12.4 & 2400.0 & 1.0 & 1.0 & 0.10 & $\sim 0.130$ \\
\end{tabular}

Коэффициенты $U_{a}, U_{b}, U_{c}$ имеют вполне физический смысл, а их размерности совпадают с размерностью $\Delta G\left[U_{a}\right]=\left[U_{b}\right]=\left[U_{c}\right]=[\Delta G]=[\mathrm{J} / \mathrm{mol}]$.

Обратим внимание на знак „-““ перед третьим слагаемым в уравнении (6). Обычно знак минус относят к коэффициенту $U_{b}$. Учитывая, что $U_{a}>0, U_{b}>0, U_{c}>0$, значение знака, скорее всего, связано со свойством инварианта третьего порядка в нечетной степени $Q^{3}$. В четной степени $Q^{2}$ и $Q^{4}$ знаки положительны, а в нечетной при $Q^{3}$ матрица тензора может быть и отрицательной. Поэтому физический смысл имеют выражения (6) и (7) со знаком минус перед слагаемым $U_{b} Q^{3}$.

При $Q=0$ из выражения (7) следует $\Delta G_{L M}=0$, $G_{M}=G_{L}$. Это означает, что на границе жидкокластерного состояния $(M)$ и изотропной жидкости $(L)$ в равновесных условиях нет фазового перехода, но они сосуществуют между собой. При $Q=1$ и на границе $M$ и анизотропного кристалла $(C)$ также нет фазового перехода, так как $\Delta G_{M S}=0$ и $G_{M}=G_{S}$ (рис. 3).

Согласно [20,23], параметр порядка лежит в пределах от нуля (изотропная жидкость) до единицы (идеальный анизотропный кристалл).

Рассмотрим значения $\Delta G_{L M}$ в зависимости от $Q$ в интервале $0 \leq Q \leq 1$ в области мезофазы. Из условия $\partial\left(\Delta G_{L M}\right) / \partial Q_{p, T}=0$ получаем из (7) уравнение

$$
4 U_{c} Q^{2}-3 U_{b} Q+2 U_{a}=0
$$

откуда

$$
Q_{1,2}=Q_{0}(1 \pm \sqrt{1-\xi}),
$$

где $Q_{0}=3 U_{b} / 8 U_{c}, \xi=32 U_{a} U_{c} / 9 U_{b}^{2}$.

Далее находим вторую производную от (7):

$$
\partial^{2}\left(\Delta G_{L M}\right) / \partial Q^{2}=8 U_{c} Q-3 U_{b} .
$$

Расчеты показывают, что, например, при $U_{a}=U_{c}=1.4 \mathrm{eV} \quad$ и $\quad U_{b}=3 \mathrm{eV}: \quad Q_{0} \approx 0.8, \quad \xi=0.74$, $Q_{2} \approx 1.24, Q_{2} \approx 0.36$. Параметр $Q_{1}>1$, поэтому мы его не учитываем. Подставляя параметр $Q_{2}$ в $(10)$, получаем соответственно $8 U_{c} Q_{2}-3 U_{b}<0$. Следовательно, при $Q_{2}$ имеем максимум $\Delta G_{\max }$.

График зависимости $\Delta G_{L M}=f(Q)$ имеет вид, показанный на рис. 4, пунктирная кривая. Эта кривая соответствует значениям $U_{a}=U_{c}=1.4 \mathrm{eV}$ и $U_{b}=3 \mathrm{eV}$. Максимальное значение $\Delta G_{\max }$, соответствующее работе $A_{C}$ образования кластера, составляет $0.068 \mathrm{eV}$.
Сравним работу $A_{C}=\Delta G_{L M}$ образования кластера при переходе из изотропной жидкости $L$ в мезофазу $M$ с работой $A_{N}=\Delta G_{M S}$ формирования кристаллического зародыша при переходе из мезофазы $M$ в твердое состояние $S$. Для этого воспользуемся уравнением зависимости изменения свободной энергии от размера $l$ зародыша кубической формы [1-3]:

$$
\Delta G_{M S}=-\Delta q l^{3}+\sigma l^{2}
$$

где $\Delta q=\rho_{S} \Delta H-c_{p} \Delta \rho\left(T_{L}-\Delta T^{-}\right)[26], \rho_{S}$ и $c_{p}, \Delta H$ плотность и теплоемкость твердой фазы, $T_{L}$ и $\Delta H$ температура и энтальпия плавления, $\Delta \rho-$ разность плотностей между жидкой $\rho_{L}$ и твердой $\rho_{S}$ фазами, $\Delta T^{-}$- переохлаждение, $\sigma$ - поверхностное натяжение на границе кристалл-жидкость.

Для конкретных расчетов были выбраны олово, висмут, вода и нафталин. Пользуясь справочными данными $[1,19]$, были рассчитаны работы $A_{C}$ для этих веществ при $\Delta T^{-}=10 \mathrm{~K}$. Результаты представлены в табл. 2.

Для построения графика зависимости $\Delta G_{M S}$ от $l$ по формуле (11) в качестве примера было выбрано олово (рис. 4, сплошная кривая).

$l, \mathrm{~nm}$

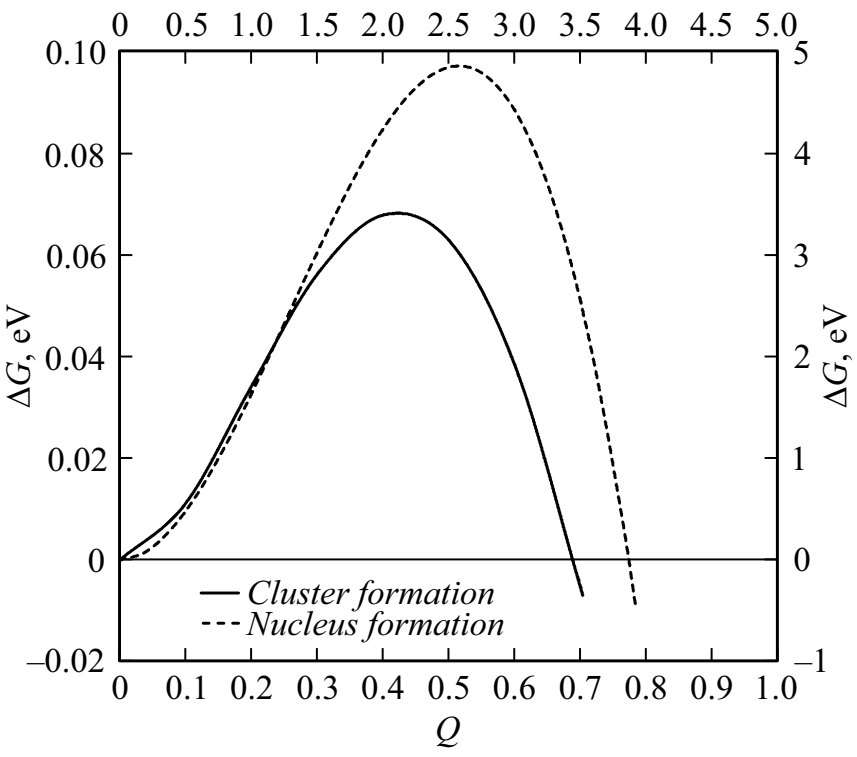

Рис. 4. Зависимости изменения свободной энергии: от параметра порядка (сплошная кривая) и от размеров зародышей (пунктирная кривая). 
Сравнивая кривые на рис. 4 между собой, видим, что для образования кластеров требуется меньше работы, чем для устойчивого кристаллического зародыша.

\section{Заключение}

На основании термограмм нагревания и охлаждения различных веществ проанализированы причины перехода от равновесной кристаллизации (ЕC) жидкой фазы к неравновесно-взрывной (NEC). Переходы ЕC $\leftrightarrow$ NEC трактуются с точки зрения кластерного строения жидкости вблизи температуры плавления. Сделана попытка адаптации известных положений теории жидких кристаллов к этим переходам. Показана корреляция между зависимостью энергии Гиббса от параметра порядка для кластеров в мезофазе и зависимостью этой энергии от размеров зародышей кристаллов в метастабильной фазе.

\section{Конфликт интересов}

Авторы заявляют, что у них нет конфликта интересов.

\section{Список литературы}

[1] Б. Чалмерс. Теория затвердевания. (Металлургия, М, 1968).

[2] М. Флеминг. Процессы затвердевания. (Мир, М., 1977).

[3] В.Д. Александров. Кинетика зародышеобразования и массовой кристаллизащии переохлажденных жмидкостей и аморфных сред. (Донецк, Донбасс, 2011).

[4] В.И. Данилов. Строение и кристаллизация жсидкости. (АН УССР, Киев, 1956).

[5] В.И. Архаров. ФТТ, 9, 73 (1979).

[6] В.И. Большаков. Теор. и практ. металлургия, 5-6, 120 (2010).

[7] Н.К. Толочко, А.А. Андрушович. Литье и металлургия, 4 (73), 59 (2013).

[8] М.П. Коробкова, В.П. Максимов, В.П. Черпаков. В сб. Некоторые вопросы физики твердого тела. (ВПИ, Воронеж, 1969). С. 159-165.

[9] М.Я. Дашевский, А.Н. Потерухин. Неорганич. матер., $4(5), 689$ (1968).

[10] В.А. Ефимов, А.С. Эльдарханов. Технологии современной металлургии. (Новые технологии, М., 2004).

jbibitem110но Ацуми, Мотэги Тэцунти. Metals, 32 (12), 1228 (1968).

[12] Ю.О. Кантер, Ю.Г. Сидоров. 6-ая междунар. конф. по росту кристаллов. Расширенные тезисы, 1980, Т. 2. С. 18 19.

[13] В.М. Глазов. Неорганич. матер., 6 (10), 1775 (1970).

[14] С.Н. Задумкин, Х.И. Ибрагимов, Д.Т. Озниев. Цветная металлургия, 1, 82 (1979).

[15] О.В. Копач. Структурні перетворення поблизу температури плавлення при синтезі нелегованого та легованого кадмійтелуриду. Дис. канд. наук. Чернівці. Черн. нац. ун-т. 2004. 189 с.

[16] Б.И. Кидяров. Механизм кинетика образования и выращивание нелинейных кристаллов для оптоэлектроники. Автореферат докт. дис. Новосибирск. 2011. 40 с.
[17] В.Д. Александров, А.А. Баранников. Спосіб термічного аналізу. Патент № 33399А. 15.02.2001. Бюл. № 1.

[18] В.Д. Александров, С.А. Фролова, В.А. Постніков, С.В. Прокоф'єв. Спосіб сумісного ииклічного та диференційного термічного аналізу. Патент № 83721 11.08.2008. Бюл. № 15.

[19] Таблица физических величин. Справочник. Под ред. И.К. Кикоина. (Атомиздат, М., 1976).

[20] А.С. Сонин. Введение в физику жсидких кристаллов. (Наука, М., 1983).

[21] А.Г. Стромберг, Д.П. Семченко. Физическая химия. (Высшая школа, М., 2001).

[22] В.Д. Александров, Е.А. Покинтелица, А.Ю. Соболев. ЖТФ, 87 (5), 722 (2017).

[23] И.Г. Чистяков, С.А. Пикин. Жидкие кристаллы. В сб. Современная кристаллография. Т. 4. (Наука, М., 1981). C. $425-472$.

[24] А.Ф. Скрышевский. Структурный анализ жсидкостей и аморбных тел. (Высшая школа, М., 1980).

[25] Л.И. Татаринова. Структура твердых аморфных и жидких веществ. (Наука, М., 1983).

[26] В.Д. Александров, Е.А. Покинтелица. Журнал физической химии, 90 (9), 1 (2016). 